This is the author's manuscript for publication. The publisher-formatted version may be available through the publisher's web site or your institution's library.

\title{
Efficacy of partial treatment of wheat with spinosad against Rhyzopertha dominica (F.) adults
}

Bhadriraju Subramanyam, Dhana Raj Boina, Blossom Sehgal, and Fernanda Lazzari

\section{How to cite this manuscript}

If you make reference to this version of the manuscript, use the following information:

Subramanyam, B., Boina, D. R., Sehgal, B., \& Lazzari, F. (2014). Efficacy of partial treatment of wheat with spinosad against Rhyzopertha dominica (F.) adults. Retrieved from http://krex.ksu.edu

\section{Published Version Information}

Citation: Subramanyam, B., Boina, D. R., Sehgal, B., \& Lazzari, F. (2014). Efficacy of partial treatment of wheat with spinosad against Rhyzopertha dominica (F.) adults. Journal of Stored Products Research, 59, 197-203.

Copyright: @ 2014 Elsevier Ltd.

Digital Object Identifier (DOI): doi:10.1016/j.jspr.2014.08.002

Publisher's Link:

http://www.sciencedirect.com/science/article/pii/S0022474X14000848

This item was retrieved from the K-State Research Exchange (K-REx), the institutional repository of Kansas State University. K-REx is available at http://krex.ksu.edu 
$1 \quad$ For: Journal of Stored Products Research

2

3

4

5

6

7

8

9 Revised version, SPR-D-14-00141

10 Subramanyam et al.: Partial grain treatment and spinosad efficacy

11

18 *Corresponding author. Tel.: + 1785532 4092: Fax: +1 7855327010 .

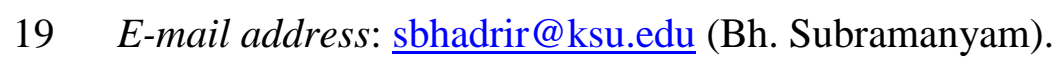

$20{ }^{\Uparrow}$ Current address: National Institute of Plant Health Management, Department of Agriculture

21 and Cooperation, Ministry of Agriculture, Government of India, Rajendranagar, Hyderabad

22 500030, Andhra Pradesh, India.

\section{Address correspondence to:}

Bhadriraju Subramanyam

Dept. of Grain Science \& Industry

Kansas State University

Manhattan, KS 66506 USA

Tel: 785-532-4092

Fax: 785-532-7010

Email: sbhadrir@ksu.edu adults Bhadriraju Subramanyam*, Dhana Raj Boina ${ }^{\natural^{\natural}}$, Blossom Sehgal, and Fernanda Lazzari Department of Grain Science and Industry, Kansas State University, Manhattan, KS 66506, USA 


\section{Abstract}

2 The efficacy of partial treatment of wheat with spinosad against adults of the lesser grain borer,

3 Rhyzopertha dominica (F.), was evaluated by mixing spinosad-treated and untreated wheat

4 kernels in varying proportions. Spinosad was applied to wheat kernels either by dipping in $1 \mathrm{mg}$

5 (a.i.) $\mathrm{ml}^{-1}$ spinosad solution for 1 minute or admixed with dry and liquid spinsoad formulations at

60.1 and the labeled rate of $1 \mathrm{mg}$ (a.i.) $\mathrm{kg}^{-1}$ of wheat. In the kernel dipping method, the percentage

7 of kernels treated was increased from 10 to 100 in $10 \%$ increments, while keeping the total

8 number of kernels at either 10 or 100 . The mortality of introduced adults in independent samples

9 was observed over time at 1 to $209 \mathrm{~h}$ post-infestation. In the admixture method, the percentage of

10 spinosad-treated wheat ranged from 10 to 100 in $10 \%$ increments by varying amounts of

11 spinosad-treated and untreated wheat to form a total of $50 \mathrm{~g}$. Mortality of introduced R. dominica

12 adults was determined after $1,3,5$, and $7 \mathrm{~d}$. In the kernel dipping method, there was an inverse

13 relationship between lethal times for 50 and $95 \%$ mortality of $R$. dominica adults and percentage

14 of kernels treated. In the admixture method, adult mortality increased with an increase in

15 spinosad rate, exposure time, and percentage of kernels treated. The liquid formulation was more

16 effective against $R$. dominica than the dry formulation. At the labeled rate of $1 \mathrm{mg}($ a.i. $) \mathrm{kg}^{-1}$,

17 treating 20 to $90 \%$ of the kernels with liquid or dry formulation of spinosad was as good as

18 treating $100 \%$ of the kernels in controlling $R$. dominica adults within 3 to $5 \mathrm{~d}$. In practical

19 situations where uneven distribution of spinosad on kernels is expected, complete control of $R$.

20 dominica adults can be achieved if more than $50 \%$ of the kernels receive spinosad treatment.

22 Keywords: Rhyzopertha dominica; Spinosad; Partial grain treatment; Efficacy 


\section{Introduction}

Spinosad is a commercial insecticide based on the fermentation products of a soil microorganism, Saccharopolyspora spinosa (Mertz and Yao) (Mertz and Yao, 1990). It was registered by the United States Environmental Protection Agency (US-EPA) in 2005 as a grain protectant at $1 \mathrm{mg}$ (a.i.) $\mathrm{kg}^{-1}$ of grain (Hertlein et al., 2011). Spinosad persists for six months up to a year on stored wheat (Fang et al., 2002a; Flinn et al., 2004; Subramanyam et al., 2007), and is extremely effective against the adults of the lesser grain borer, Rhyzopertha dominica (F.) (Coleoptera: Bostrichidae), including strains resistant to organophosphates (OPs), pyrethroids, or juvenile hormone analogs (Nayak et al., 2005; Daglish and Nayak, 2006; Daglish et al., 2008). A grain protectant is applied to uninfested grain as it is augured into a bin for long-term protection against insect infestation. During this process, uneven distribution of insecticide on kernels may occur, resulting in some kernels being treated completely while others only partially treated or left completely untreated. For instance, treatment of wheat with spinosad at $1 \mathrm{mg}$ (a.i.) $\mathrm{kg}^{-1}$ of grain as it was augured into farm bins resulted in residue deposition of only $0.7 \mathrm{mg}$ (a.i.) $\mathrm{kg}^{-1}$ immediately after treatment (Subramanyam et al., 2007). Even in carefully controlled laboratory conditions, treating wheat with spinosad at $0.1,0.5,1.0,3.0$, and $6.0 \mathrm{mg}$ (a.i.) $\mathrm{kg}^{-1}$, on an average, resulted in residue deposition of only $75 \%$ of the actual rates applied (Fang et al., 2002b). In $4.72 \mathrm{~m}$ diameter and $3.35 \mathrm{~m}$ high round steel bins holding 30.7 metric tons of $10.8 \%$ moisture wheat, Flinn et al. (2004) reported that spinosad deposition soon after treatment at $1 \mathrm{mg}$ (a.i.) $\mathrm{kg}^{-1}$ ranged from 0.40 to $0.88 \mathrm{mg}$ (a.i.) $\mathrm{kg}^{-1}$. The actual spinosad residue deposition varied in samples taken near the bin periphery and bin center and in the top, middle, and bottom portions of the grain mass. Despite these variations, the efficacy of spinosad against $R$. dominica was unaffected, because adults of $R$. dominica generally are more susceptible to spinosad than 
1 adults of other stored-product insect species (Fang et al., 2002a, b; Flinn et al., 2004;

2 Subramanyam et al., 2007).

The effect of partial treatment of wheat with malathion was evaluated by Minett and

4 Williams (1971, 1976), and with $S$-methoprene by Daglish and Nayak (2010). In these studies,

5 varying proportions (0.1-100\%) of wheat kernels were treated with the insecticide at a higher

6 rate and later mixed with the remaining untreated grain mass to get the same overall level of the

7 insecticide for the entire grain mass. However, this method may have resulted in higher

8 insecticide residues on individual kernels. The concept of treating only a portion of wheat

9 kernels proportionately reduces the cost of grain treatment by reducing the amount of insecticide

10 and labor required as well as total residues on kernels.

11 In the present investigation, a series of laboratory tests was carried out to determine the

12 effect of partial treatment of wheat kernels with spinosad against $R$. dominica adults. Two

13 bioassay methods of treating wheat kernels were used. One involved dipping wheat kernels in an

14 aqueous solution of spinosad, and other involved directly treating kernels with dry and liquid

15 spinosad formulations after which treated kernels were combined with untreated kernels in

16 different proportions. Directly treating kernels with spinosad may still result in some kernels not

17 receiving the insecticide, therefore, the dipping method was used to eliminate this effect. These

18 experiments were conducted to determine time to death of $R$. dominica adults exposed to

19 spinosad. Time to death is of interest because it is important to prevent oviposition before death

20 in this species where the immature stages develop within kernels. 


\section{2. Materials and methods}

2 2.1. Wheat, insect cultures, and spinosad formulations

3 Organic, hard red winter wheat (Heartland Mills, Marienthal, KS, USA) was cleaned

4 manually by sieving it over a 2-mm round hole sieve (Seedburo Equipment Co., Chicago, IL,

5 USA) to remove dockage and broken kernels. Cleaned wheat was frozen for one week at $-13^{\circ} \mathrm{C}$

6 to kill any live insects present. Cultures of $R$. dominica were maintained on organic, hard red

7 winter wheat of $\sim 12 \%$ moisture in a growth chamber at $28^{\circ} \mathrm{C}$ and $65 \%$ relative humidity (r.h.) in

8 the Department of Grain Science and Industry, Kansas State University, Manhattan, KS, USA.

9 These insects have been in rearing since 1999. The liquid and dry formulations of spinosad

10 (Bayer CropScience, Research Triangle Park, NC, USA) contained 8.66\% (w/v) and 0.5\% (w/w)

11 a.i. of spinosad, respectively.

12 2.2. Wheat kernel treatment by dipping method

13 In the first experiment, the liquid spinosad formulation was diluted in distilled water to

14 make a $1000 \mathrm{ml}$ solution containing $1 \mathrm{mg}$ (a.i.) $\mathrm{ml}^{-1}$ of spinosad. Four $500 \mathrm{~g}$ lots of wheat were

15 dipped in the spinosad solution for one minute. Wheat kernels dipped similarly in distilled water

16 served as controls. All dipped kernels were dried on paper towels, and held at $28^{\circ} \mathrm{C}$ and $65 \%$ r.h.

17 for one week to equilibrate the moisture content. There were a total of 11 treatments. The control

18 treatment consisted of gluing 10 water-treated kernels in a grid fashion in 9-cm diameter glass

19 Petri dishes. The spinosad treatments included 1 to 10 treated kernels in 1 kernel increments with

209 to 0 water-treated kernels to give 10 to $100 \%$ of spinosad-treated kernels. Ten unsexed, two- to

21 three-week-old adults of $R$. dominica were released in the center of each Petri dish. The dishes

22 were covered with lids and held at room conditions $\left(25^{\circ} \mathrm{C}\right.$ and $46 \%$ r.h.). Each treatment dish

23 was observed over time on 29 occasions, 1 to $105 \mathrm{~h}$ at $4 \mathrm{~h}$ increments ( 27 occasions) and at 173 
1 and $209 \mathrm{~h}$ after adult introduction to count number of dead and live adults. Each spinosad

2 treatment and observation time combination was replicated four times and separate dishes were 3 used for each treatment combination.

4 In the second experiment, wheat kernels were treated with $1 \mathrm{mg}$ (a.i.) $\mathrm{ml}^{-1}$ of spinosad as 5 described above using 100 spinosad-treated and/or water-treated (control) kernels taken in

6 different proportions in transparent plastic vials $(2.5 \mathrm{~cm}$ diameter by $5.0 \mathrm{~cm}$ high) with a

7 screened lid. The control treatment consisted of 100 water-treated kernels; the remaining 10

8 treatments included 10 to 100 spinosad-dipped kernels mixed with 90 to 0 water-treated kernels

9 to give 10 to $100 \%$ of kernels treated with spinosad. After adding kernels, the vials were closed

10 with lids and turned upside down five times to mix the kernels. In each vial, 10 unsexed two- to

11 three-week-old $R$. dominica adults were released on the top of kernels after which the vials were

12 closed with lids and held at room conditions. These vials were examined at 19 observation times

13 starting at $1 \mathrm{~h}$ and ending at $73 \mathrm{~h}$ in $4 \mathrm{~h}$ increments. Independent vials were examined at each

14 observation time. Each spinosad treatment and observation time combination was replicated

15 three times.

\section{2.3. Residue analysis}

17 In the kernel dipping method, the deposition of spinosad residues on grain may exceed

18 the maximum tolerance level of $1.5 \mathrm{mg} \mathrm{kg}^{-1}$ of grain, established by the US-EPA (Hertlein et al.,

19 2011). Therefore, residue analysis of whole wheat kernels dipped in $1 \mathrm{mg}$ (a.i.) $\mathrm{ml}^{-1}$ spinosad

20 solution was conducted by Dow AgroSciences, Indianapolis, IN, USA, using methods described

21 by Hastings and Clements (2000). Only one sample was submitted to Dow AgroSciences for

22 residue analysis. 
The objective of this experiment was to determine the efficacy of spinosad against $R$.

3 dominica adults when a portion of wheat kernels was treated with spinosad and then mixed with

4 untreated kernels. Wheat kernels were treated with both dry and liquid formulations of spinosad

5 at $0,0.1$ and $1.0 \mathrm{mg}$ (a.i.) $\mathrm{kg}^{-1}$ of grain. The total quantity of wheat kernels required for all

6 treatments in a replication $(275 \mathrm{~g})$ was treated together either by adding $275 \mu \mathrm{l} \mathrm{of} 1 \mathrm{mg}$ (a.i.) $\mathrm{ml}^{-1}$

7 solution (liquid formulation) or $55 \mathrm{mg}$ of dust (dry formulation) to obtain the target rate of 1.0

$8 \mathrm{mg}$ (a.i.) $\mathrm{kg}^{-1}$ of grain. Treated and untreated wheat kernels were mixed in different proportions

9 in $150 \mathrm{ml}$ plastic containers by increasing the quantity of treated wheat kernels in $5 \mathrm{~g}$ increments,

10 keeping the total quantity of wheat at $50 \mathrm{~g}$ i.e. treated: untreated in $0: 50,5: 45,10: 40, \ldots 45: 5$, and

$1150: 0 \mathrm{~g}$ (equivalent to $0,10,20, \ldots 90$, and 100 percent of kernels treated, respectively). The

12 containers were closed with lids and turned upside down 10 times to mix wheat kernels in each

13 container. Twenty five unsexed (two- to three-week-old) adults of $R$. dominica were introduced

14 into each container and the containers were fitted with screen lids and placed in a growth

15 chamber at $28^{\circ} \mathrm{C}$ and $65 \%$ r.h. Each combination of spinosad formulation, rate, and percentage

16 kernels treated was replicated three times. The adult mortality was examined at 1, 3, 5, and $7 \mathrm{~d}$

17 after adult introduction on the same set of samples.

\section{2.5. Statistical analyses}

The treatment mortality data over time from whole kernel dipping method were corrected

20 for respective control mortality data (Abbott, 1925). The corrected mortality data were subjected

21 to probit regression analysis to estimate the lethal times required for 50\% (LT $\left.\mathrm{LT}_{50}\right)$ and $95 \%\left(\mathrm{LT}_{95}\right)$

22 adult mortality and associated statistics (SAS Institute, 2008). Linear or nonlinear models were 
1 fit to the relationship between percentage of kernels treated and $\mathrm{LT}_{50}$ or $\mathrm{LT}_{95}$ values using Table

2 Curve 2D software (Jandel Scientific, San Rafael, CA, USA).

3 Mortality data by day from experiments with spinosad by admixing method were

4 corrected for respective control mortality. The corrected mortality data were transformed to

5 angular values for normalizing variances (Zar, 1984). The data were subjected to a one-way

6 analysis of variance (ANOVA) and means were separated using Bonferroni $t$-tests at $\alpha=0.05$

7 (SAS Institute, 2008).

9 3. Results

10 3.1. Wheat treatment by dipping whole kernels in spinosad solution

11 Irrespective of the total number of kernels used, $\mathrm{LT}_{50}$ and $\mathrm{LT}_{95}$ values decreased as the

12 percentage of kernels treated increased from 10 to 100 . However, the magnitude of decrease was

13 higher at $\mathrm{LT}_{95}$ than at $\mathrm{LT}_{50}$ when total number of kernels was 10 (Table 1), while it was more or

14 less similar at both $\mathrm{LT}_{50}$ and $\mathrm{LT}_{95}$ when total number of kernels was 100 (Table 2). The Pearson

15 goodness-of-fit Chi-square $\left(\chi^{2}\right)$ test showed that the probit model fit to data was significant $(P<$

16 0.05) for 18 out of the 20 probit regressions shown in Tables 1 and 2, indicating poor fit of

17 model to data. Fitting logit and complementary log-log models to data (Robertson and Priesler,

18 1992) also yielded similar results, suggesting that the responses of adults were heterogeneous. In

19 cases where the $P$-value for the test is low, variances and covariances are adjusted by a

20 heterogeneity factor (Chi-square value divided by the degrees of freedom (df)), and a critical

21 value from the $t$ distribution is used to compute the confidence limits (SAS Institute, 2008).

22 The relationship between percentage of kernels treated and $\mathrm{LT}_{50}$ or $\mathrm{LT}_{95}$ values was

23 satisfactorily described by linear $(y=a+b x)$ or nonlinear $(y=a+b / x)$ models $\left(r^{2}=0.51-0.94\right)$ 
1 (Fig. 1A-D), and the model parameters are given in Table 3. When number of kernels treated

2 was 10 , the $\mathrm{LT}_{50}$ and $\mathrm{LT}_{95}$ values decreased in a non-linear fashion with increase in percentage

3 of kernels treated. However, when number of kernels treated was 100 , the $\mathrm{LT}_{50}$ values decreased

4 linearly and the $\mathrm{LT}_{95}$ values decreased in a non-linear fashion with increase in percentage of

5 kernels treated.

\section{3.2. Residue analysis}

7 Dipping the whole wheat kernels in $1 \mathrm{mg}$ (a.i.) $\mathrm{ml}^{-1}$ spinosad solution resulted in a

8 deposit of $11.9 \mathrm{mg}$ (a.i.) $\mathrm{kg}^{-1}$ of wheat. This is nearly eight times higher than the tolerance limit 9 of $1.5 \mathrm{mg}$ (a.i.) $\mathrm{kg}^{-1}$ on wheat.

10 3.3. Wheat treatment with spinosad by admixing

11 The adult mortality in control treatments ( $0 \%$ treated kernels) in tests with both liquid and 12 dry spinosad formulations ranged from 0 to $2.7 \%$. Irrespective of the spinosad formulation and 13 rate used, mortality increased with increase in percentage of kernels treated and exposure time 14 (Tables 4 and 5 and Fig 2A-D). There were significant differences in mortality due to percentage

15 of kernels treated with liquid formulation of spinosad at $0.1 \mathrm{mg}($ a.i $) \mathrm{kg}^{-1}$ at $1\left(F_{9,20}=8.38 ; P<\right.$ $160.0001), 3\left(F_{9,20}=46.84 ; P<0.0001\right), 5\left(F_{9,20}=35.71 ; P<0.0001\right)$, and $7\left(F_{9,20}=36.30 ; P<\right.$

17 0.0001) days after exposure. At $1 \mathrm{~d}$ after exposure, the maximum mortality was only $15 \%$. At

18 subsequent observations days, mortality increased several fold. At 3, 5, and $7 \mathrm{~d}$ after exposure,

19 the cumulative mortality was $\geq 50 \%$ in treatments with 60,40 , and $30 \%$ of kernels treated,

20 respectively (Table 4). Overall, treating $\geq 30 \%$ of kernels resulted in $\geq 50 \%$ mortality after $7 \mathrm{~d}$ and

21 higher the percentage of kernels treated, lower the time required for 50\% mortality. Treating

$22 \geq 90 \%$ of kernels resulted in $100 \%$ adult mortality after $5 \mathrm{~d}$ of exposure (Fig. 2A). 
At $1 \mathrm{mg}$ (a.i.) $\mathrm{kg}^{-1}$, the adult mortality in all the treatments was higher compared to a

2 similar exposure at $0.1 \mathrm{mg}$ (a.i.) $\mathrm{kg}^{-1}$ of grain (Table 4). Significant differences in mortality were

3 observed due to percentage of kernels treated at $1\left(F_{9,20}=29.60 ; P<0.0001\right), 3\left(F_{9,20}=16.44 ; P\right.$

$4<0.0001)$, and $5\left(F_{9,20}=4.00 ; P=0.0047\right)$ days after exposure. At 1 day after exposure, $>50 \%$

5 adult mortality was obtained by treating $70 \%$ of kernels. At 3, 5, and $7 \mathrm{~d}$ after exposure even

6 treating $10 \%$ of kernels resulted in $\geq 70, \geq 97$ and $100 \%$ mortality (Table 4). Overall, treating 20

7 to $60 \%$ of kernels resulted in $>50$ and $100 \%$ mortality after 3 and $5 \mathrm{~d}$ of exposure, respectively.

8 Treating $\geq 70 \%$ of kernels resulted in $>50 \%$ mortality after $1 \mathrm{~d}$ and $100 \%$ mortality after $3 \mathrm{~d}$ (Fig.

$92 \mathrm{~B})$.

10 Except for the slightly lower mortality with dry spinosad compared to liquid spinosad, the

11 general trend and degree of adult mortality with dry spinosad at $0.1 \mathrm{mg}(\mathrm{a.i}) \mathrm{kg}^{-1}\left(F_{9,20}=4.48-\right.$

$1248.48 ; P<0.0001-0.0025)$ and at $1 \mathrm{mg}(\mathrm{a} . \mathrm{i}) \mathrm{kg}^{-1}\left(F_{9,20}=5.89-24.61 ; P<0.0001-0.0005\right)$ was

13 similar to that obtained with liquid spinosad (Table 5). Additionally, the time required for 50 and

$14100 \%$ mortality was similar to that of liquid spinosad at the respective rates (Fig. 2C and D)

15 except that a 2 d longer exposure was required for $100 \%$ mortality when $90 \%$ of kernels were

16 treated at lower rate and $\geq 70 \%$ of kernels were treated at the higher rate (Fig. $2 \mathrm{C}$ and D).

18 4. Discussion

19 The present study evaluated the efficacy of spinosad against $R$. dominica adults when a

20 portion of wheat kernels were treated either by dipping in spinosad solution or kernels were

21 treated with dry and liquid spinosad formulations at the labeled rate and one-tenth the labeled

22 rate and then admixed treated and untreated kernels in different proportions. In the kernel

23 dipping method where there was uniform coating of spinosad of kernels, there was an inverse 
1 relationship between the percentage of kernels treated and lethal times for mortality of $R$.

2 dominica adults, despite the fact that the responses of $R$. dominica adults over time at each

3 percentage of treated kernels were heterogeneous. Heterogeneous responses of adults could be

4 due to age-related or sex-related differences in susceptibility as unsexed adults of two- to three-

5 weeks of age were used in the experiments. Additionally, extent and duration of contact with

6 spinosad-treated kernels or ingestion of spinosad-treated kernels may have contributed to this

7 unexplained heterogeneity, which was also influenced by the kernel density and percentage of

8 kernels treated with spinosad. For example, the lethal times for 50\% and 95\% mortality of $R$.

9 dominica adults among percentage of kernels treated generally were longer when 10 kernels were

10 used as opposed to 100 kernels. This can be attributed to the fact that there were 10 times more

11 kernels with 100 than with 10 kernels. As a result $R$. dominica adults may be coming in frequent

12 contact with treated kernels or feeding more on spinosad-treated kernels when 100 kernels were

13 used. The fact that the lethal times for $50 \%$ or $95 \%$ mortality of $R$. dominica adults did not

14 change substantially with an increase in percentage of kernels treated from 10 to 100 when 100

15 kernels were used further supports the above explanation. Carefully designed behavioral

16 experiments may shed light on the unexplained heterogeneity observed in our study.

17 Kernel treatment by dipping in $1 \mathrm{mg}$ (a.i.) $\mathrm{ml}^{-1}$ solution resulted in a spinosad residue

18 deposit nearly eight times higher than the tolerance level of $1.5 \mathrm{mg}(\mathrm{a} . \mathrm{i}) \mathrm{kg}^{-1}$ of grain. In real

19 world situations, uniform coating of kernels with insecticide is rare and uneven distribution of

20 insecticide on kernels and uneven distribution of treated kernels in a grain lot are very common

21 (Flinn et al., 2004; Subramanyam et al., 2007). When grain is treated with an insecticide as it is

22 being augured into the storage bins, not all kernels are treated uniformly and some kernels are

23 not treated at all, and this may result in percentage of treated and untreated kernels to range 
1 anywhere between 10 and 100 . In a laboratory study, treating only $1 \%$ of wheat kernels with a

2 high rate of malathion (1000 $\mathrm{mg}$ (a.i.) $\mathrm{kg}^{-1}$ ) and mixing them with untreated grain mass to give a

3 final rate of $10 \mathrm{mg}$ (a.i.) $\mathrm{kg}^{-1}$ of grain resulted in effective control of the rice weevil, Sitophilus

4 oryzae (L.), confused flour beetle, Tribolium confusum Jacqueline du Val, and $R$. dominica

5 adults and suppression of progeny production for 70 to 100 days. These results were comparable

6 to treating all grains at $10 \mathrm{mg}$ (a.i.) $\mathrm{kg}^{-1}$ (Minett and Williams, 1971). Therefore, the next set of

7 experiments were focused on treating the kernels with spinosad dry and liquid formulations at

8 the labeled rate and one-tenth the labeled rate and mixing the treated and untreated kernels in

9 different proportions to simulate variation that could occur under actual practical field

10 applications. The results showed that the liquid formulation of spinosad exhibited a slightly

11 higher activity against $R$. dominica adults than the dry formulation at a given rate. This

12 observation was confirmed in our earlier evaluations on wheat with spinosad (Getchell and

13 Subramanyam, 2008; Subramanyam et al., 2012). There was a positive relationship between

14 percentage of kernels treated or exposure time and adult mortality. At the labeled rate treating

15 only $10 \%$ of kernels resulted in near complete to complete mortality of $R$. dominica adults in 5 to

$167 \mathrm{~d}$ after exposure. However, treating a higher percentage (>10\%) of kernels reduced the

17 exposure time for near complete to complete adult mortality to 3 to $5 \mathrm{~d}$.

18 The near complete to complete adult mortality with only $10 \%$ of kernels treated may be

19 attributed to the greater susceptibility of $R$. dominica adults to spinosad and likely transfer of

20 spinosad residues from treated to untreated kernels while mixing. A similar hypothesis for

21 transfer of residues from treated to untreated wheat kernels was proposed by Daglish and Nayak

22 (2010) where treating $2 \%$ of wheat kernels with $S$-methoprene to achieve an overall rate of 0.6

$23 \mathrm{mg}$ (a.i.) $\mathrm{kg}^{-1}$ of grain. Exposing $R$. dominica adults to this rate for $14 \mathrm{~d}$ caused a significant 
1 reduction in progeny production. Moreover, a brief exposure to spinosad residues is sufficient to

2 cause mortality of $R$. dominica adults which is typically manifested as delayed toxicity, even

3 after removal of adults from treated grain (Getchell and Subramanyam, 2008; Athanassiou et al.,

4 2010; Boina et al., 2012). Athanassiou et al. (2009) reported that $83 \%$ of $R$. dominica adults were

5 dead in $14 \mathrm{~d}$ when they were released on surface of wheat kernels in a plastic vial in which only

6 top $1 / 8^{\text {th }}$ layer was treated with spinosad. This was due to brief exposure of adults to spinosad

7 residues during their downward movement through the thin treated layer (2-3 wheat kernel-deep

8 layer). In our study, $R$. dominica adults were added on the surface of grain in the plastic

9 containers and by virtue of their vertical downward movement (Surtees, 1964; Vardeman et al.,

10 2007a, b), adults were able to pick up sufficient amount of spinosad required for death even in

11 treatments where only $10 \%$ of kernels were treated.

12 Our results show that with uneven distribution of insecticide resulting from treating only

13 a few (10\%) kernels, complete mortality of $R$. dominica adults could still be achieved with a

14 longer exposure time ( $7 \mathrm{~d}$ ). However, adults surviving until day 7 in grains with uneven

15 distribution of insecticide could still mate and lay eggs as well as continue further infestation and

16 grain damage (Athanassiou et al., 2010). The results of the present study indicated that treating

17 all wheat kernels in a grain mass at a rate 10 times lower than labeled $\left(0.1 \mathrm{mg} \mathrm{kg}^{-1}\right)$ or treating

$18<50 \%$ of kernels at labeled rate results in survival of adults for a longer period of time than

19 treating all kernels at labeled rate. This may increase the chances of further infestations and

20 kernel damage. Daglish and Nayak (2010) also reported that treating a portion of wheat kernels

21 with $S$-methoprene at a lower rate of $0.03 \mathrm{mg}$ (a.i.) $\mathrm{kg}^{-1}$ than the recommended of $0.6 \mathrm{mg}$ (a.i.)

$22 \mathrm{~kg}^{-1}$, resulted in survival of adults and subsequent progeny production. 
Finally, it can be concluded that treating 20 to $90 \%$ of kernels at the labeled rate of $1 \mathrm{mg}$

2 (a.i.) $\mathrm{kg}^{-1}$ is as good as treating $100 \%$ of kernels in controlling $R$. dominica adults to reduce cost

3 of grain treatment. However, this compromises the intended quick mortality of adults and may

4 lead to some progeny production and kernel damage from adults surviving until $7 \mathrm{~d}$ after

5 treatment. In practical situations where uneven distribution of spinosad on kernels is expected,

6 complete control of $R$. dominica adults can be achieved if more than $50 \%$ of the kernels receive

7 spinosad treatment, which is more likely to prevent progeny production, subsequent infestation

8 and kernel damage from surviving adults. 


\section{Acknowledgements}

2 We would like to thank Bayer CropScience (Research Traingle Park, NC, USA) for providing

3 dry and liquid formulations of spinosad and for supporting this research and Dow AgroSciences

4 (Indianapolis, IN, USA) for conducting the whole kernel residue analysis. This paper is

5 contribution number 14-420-J of the Kansas State University Agricultural Experiment Station. 


\section{References}

2 Abbott, 1925. A method for computing the effectiveness of an insecticide. Journal of Economic Entomology 18, 265-267.

4 Athanasssiou, C.G., Arthur, F.H., Throne, J.E., 2009. Efficacy of spinosad in layer-treated wheat against five stored-product insect species. Journal of Stored Products Research 45, 236-

Athanassiou, C.G., Arthur, F.H., Throne, J.E., 2010. Effects of short exposures to spinosadtreated wheat or maize on four stored-grain insects. Journal of Economic Entomology 103, 197-202.

Boina, D.R., Subramanyam, Bh., Mutambuki, K., 2012. Delayed mortality responses of Rhyzopertha dominica (F.) adults subjected to short exposures on spinosad-treated wheat. Journal of Stored Products Research 48, 149-152.

Daglish, G.J., Head, M.B., Hughes, P.B., 2008. Field evaluation of spinosad as a grain protectant for stored wheat in Australia: efficacy against Rhyzopertha dominica (F.) and fate of residues in whole wheat and milling fractions. Australian Journal of Entomology 47, 70-74.

Daglish, G.J., Nayak, M.K., 2006. Long-term persistence and efficacy of spinosad against Rhyzopertha dominica (Coleoptera: Bostrichidae) in wheat. Pest Management Science 62, 148-152.

Daglish, G.J., Nayak, M.K., 2010. Uneven application can influence the efficacy of $s$ methoprene against Rhyzopertha dominica (F.) in wheat. Journal of Stored Products Research 46, 250-253.

Fang, L., Subramanyam, Bh., Arthur, F.H., 2002a. Effectiveness of spinosad on four classes of wheat against five stored-product insects. Journal of Economic Entomology 95, 640-650. 
1 Fang, L., Subramanyam, Bh., Dolder, S., 2002b. Persistence and efficacy of spinosad residues in farm stored wheat. Journal of Economic Entomology 95, 1102-1109.

3 Flinn, P. W., Subramanayam, Bh., Arthur, F. H., 2004. Comparison of aeration and spinosad for suppressing insects in stored wheat. Journal of Economic Entomology 97, 1465-1473.

Getchell, A.I., Subramanyam, Bh., 2008. Immediate and delayed mortality of Rhyzopertha dominica (Coleoptera: Bostrichidae) and Sitophilus oryzae (Coleoptera: Curculionidae) adults exposed to spinosad-treated commodities. Journal of Economic Entomology 101, 1022-1027.

Hastings, M., Clements, B., 2000. Determination of spinosad residues in dry agricultural crops by high performance liquid chromatography with APCI mass spectrometry detection, GRM 00.04. Report of Dow AgroSciences LLC. Dow AgroSciences, Indianapolis, IN.

Hertlein, M.B., Thompson, G.D., Subramanyam, Bh., Athanassiou, C.G., 2011. Spinosad: A new natural product for stored grain protection. Journal of Stored Products Research 47, 131146.

Mertz, F.P., Yao, R.C., 1990. Saccharopolyspora spinosa sp. nov. isolated from soil collected in a sugar mill rum still. International Journal of Systematic Bacteriology 40, 34-39.

Minett, W., Williams, P., 1971. Influence of malathion distribution on the protection of wheat grain against insect infestation. Journal of Stored Products Research 7, 233-242.

Minett, W., Williams, P., 1976. Assessment of non-uniform malathion distribution for insect control in a commercial wheat silo. Journal of Stored Products Research 12, 27-33.

Nayak, M.K., Daglish, G.J., Byrne, V.S., 2005. Effectiveness of spinosad as a grain protectant against resistant beetle and psocid pests of stored grain in Australia. Journal of Stored Products Research 41, 455-467. 
1 Robertson, J.L., Priesler, H.K., 1992. Pesticide bioassays with arthropods. CRC Press, Boca

2 Raton, FL, USA.

3 SAS Institute, 2008. SAS/STAT user's guide, version 9.2. Cary, NC, USA.

4 Subramanyam, Bh., Hartzer, M., Boina, D. R., 2012. Performance of pre-commercial release

5 formulations of spinosad against five stored-product insect species on four stored

6 commodities. Journal of Pest Science 85, 331-339.

7 Subramanyam, Bh., Toews, M.D., Ileleji, K.E., Maier, D.E., Thompson, G.D., Pitts, T.J., 2007.

8 Evaluation of spinosad as a grain protectant on three Kansas farms. Crop Protection 26,

$9 \quad 1021-1030$.

10 Surtees, G., 1964. Laboratory studies on dispersion behavior of adult beetles in grain. VI. Three-

11 dimensional analysis of dispersion of five species in a uniform bulk. Bulletin of

12 Entomological Research 55, 161-171.

13 Vardeman, E. A., Arthur, F. H., Nechols, J. R., Campbell, J. F., 2007a. Efficacy of surface

14 applications with diatomaceous earth to control Rhyzopertha dominica (F.) (Coleoptera:

15 Bostrichidae) in stored wheat. Journal of Stored Products Research 43, 335-341.

16 Vardeman, E. A., Campbell, J. F., Arthur, F. H., Nechols, J. R., 2007b. Behavior of female

17 Rhyzopertha dominica (Coleoptera: Bostrichidae) in a mono-layer of wheat treated with

18 diatomaceous earth. Journal of Stored Products Research 43, 297-301.

19 Zar, J.H., 1984. Biostatistical analysis, 2nd ed. Prentice Hall, Englewood Cliffs, NJ, USA. 


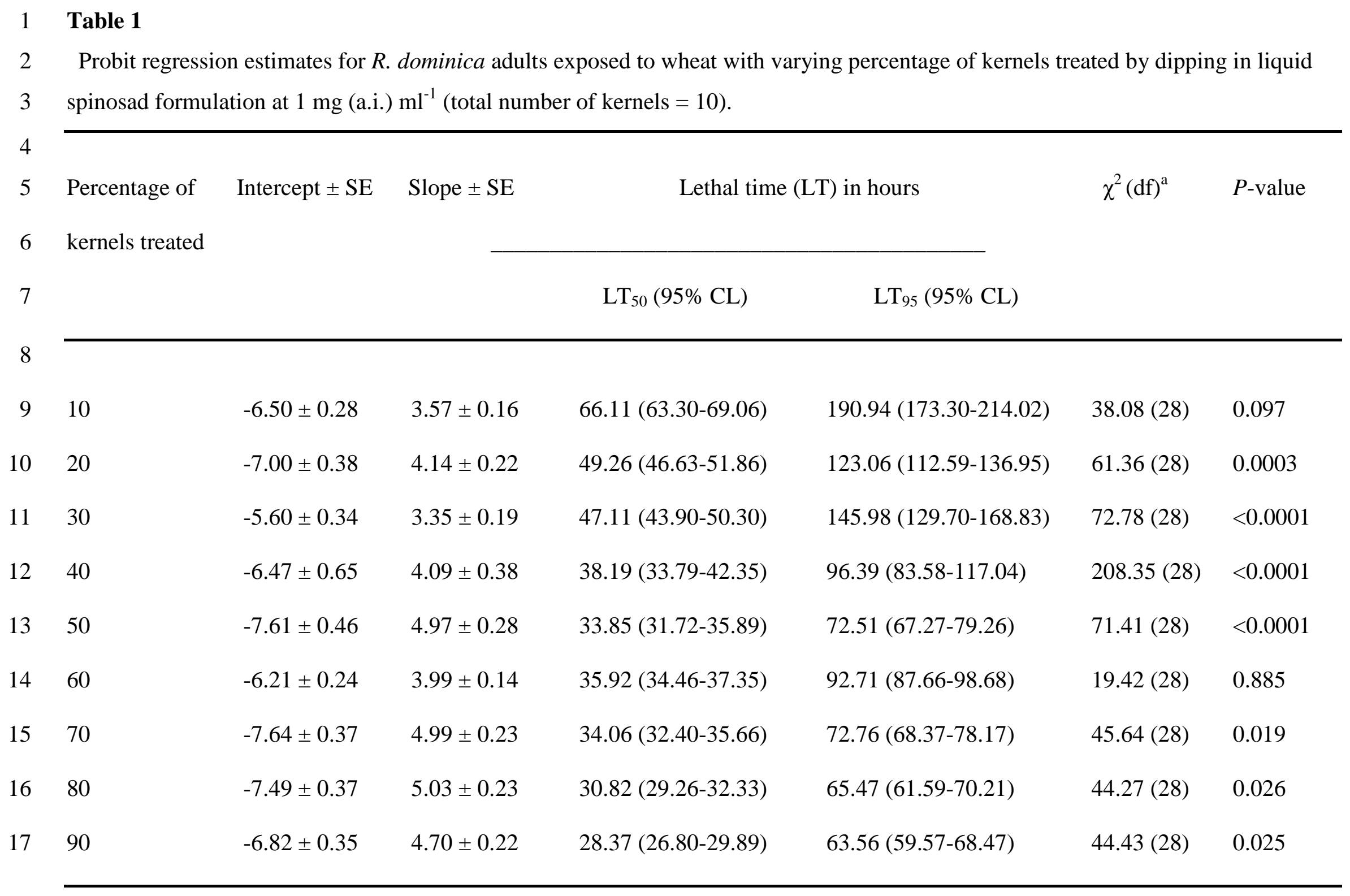


$4{ }^{\mathrm{a}}$ Chi-square value for goodness-of-fit of probit model to data. 5

6

7

8

9

10

11

12

13

14

15

16

17 


\section{Table 2}

2 Probit regression estimates for $R$. dominica adults exposed to wheat with varying percentage of kernels treated by dipping in liquid

3 spinosad formulation at $1 \mathrm{mg}($ a.i. $) \mathrm{ml}^{-1}$ (total number of kernels $=100$ ).

4

\section{6 kernels treated}

\section{8}

$9 \quad 10$

$10 \quad 20$

1130

$12 \quad 40$

1350

$14 \quad 60$

$15 \quad 70$

$16 \quad 80$

$17 \quad 90$

$\begin{array}{llllll}-9.93 \pm 0.85 & 6.46 \pm 0.53 & 34.50(32.17-36.76) & 62.03(56.55-70.14) & 67.04(17) & <0.0001 \\ -11.22 \pm 0.70 & 7.39 \pm 0.45 & 33.00(31.54-34.42) & 55.11(51.86-59.35) & 32.51(17) & 0.013 \\ -10.60 \pm 0.97 & 6.87 \pm 0.61 & 34.97(32.60-37.23) & 60.70(55.43-68.65) & 71.47(17) & <0.0001 \\ -11.97 \pm 0.76 & 7.84 \pm 0.48 & 33.64(32.18-35.05) & 54.53(51.40-58.63) & 33.77(17) & 0.009 \\ -12.34 \pm 1.15 & 8.09 \pm 0.73 & 33.60(31.47-35.62) & 53.67(49.53-59.81) & 71.04(17) & <0.0001 \\ -10.29 \pm 0.84 & 6.85 \pm 0.54 & 31.79(29.79-33.71) & 55.26(50.87-61.53) & 57.14(17) & <0.0001 \\ -10.67 \pm 0.89 & 7.10 \pm 0.57 & 31.94(29.93-33.87) & 54.47(50.19-60.62) & 59.67(17) & <0.0001 \\ -12.05 \pm 0.99 & 8.12 \pm 0.65 & 30.54(28.86-32.17) & 48.70(45.28-53.56) & 51.84(17) & <0.0001 \\ -9.66 \pm 0.68 & 6.55 \pm 0.44 & 29.87(28.17-31.51) & 53.27(49.43-58.48) & 42.36(17) & 0.0006\end{array}$

$\chi^{2}(\mathrm{df})^{\mathrm{a}} \quad P$-value

\section{$\mathrm{LT}_{50}(95 \% \mathrm{CL}) \quad \mathrm{LT}_{95}(95 \% \mathrm{CL})$}

$42.36(17) \quad 0.0006$ 
2

$3{ }^{a}$ Chi-square value for goodness-of-fit of probit model to data. 


\section{Table 3}

2 Parameter estimates of the regression models describing the relationship between percentage of

3 kernels treated with spinosad by kernel dipping method and the times for $50 \%\left(\mathrm{LT}_{50}\right)$ and $95 \%$

$4 \quad\left(\mathrm{LT}_{95}\right)$ mortality of $R$. dominica adults.

\begin{tabular}{|c|c|c|c|c|}
\hline \multirow{2}{*}{$\begin{array}{c}\text { Number of } \\
\text { kernels treated }\end{array}$} & \multirow[t]{2}{*}{ LT value } & \multicolumn{2}{|c|}{ Mean \pm SE for parameter ${ }^{a}$} & \multirow[t]{2}{*}{$r^{2}$} \\
\hline & & $a$ & $b$ & \\
\hline \multirow[t]{2}{*}{10} & $\mathrm{LT}_{50}$ & $27.06 \pm 1.46$ & $414.11 \pm 37.12$ & 0.9395 \\
\hline & $\mathrm{LT}_{95}$ & $55.48 \pm 8.56$ & $1443.77 \pm 217.38$ & 0.8464 \\
\hline \multirow[t]{2}{*}{100} & $\mathrm{LT}_{50}$ & $35.37 \pm 0.56$ & $-0.05 \pm 0.01$ & 0.8186 \\
\hline & $\mathrm{LT}_{95}$ & $52.53 \pm 1.32$ & $96.08 \pm 33.59$ & 0.5055 \\
\hline
\end{tabular}

5

$6{ }^{a}$ Ten observations were used when fitting regression models to $\mathrm{LT}_{50}$ and $\mathrm{LT}_{95}$ versus percentage

7 of kernels treated data.

8 


\section{Table 4}

2 Mortality of $R$. dominica adults on wheat with varying percentage of kernels treated with two

3 rates of spinosad liquid formulation at different exposure times.

\begin{tabular}{|c|c|c|c|c|c|}
\hline \multirow{3}{*}{$\begin{array}{c}\text { Rate } \\
(\mathrm{mg} \text { a.i. } \\
\left.\mathrm{kg}^{-1}\right)\end{array}$} & \multirow{3}{*}{$\begin{array}{l}\text { Percentage of } \\
\text { kernels treated }\end{array}$} & \multicolumn{4}{|c|}{ Mean \pm SE mortality at exposure time in days ${ }^{a}$} \\
\hline & & 1 & 3 & 5 & 7 \\
\hline & & & & & \\
\hline \multirow[t]{10}{*}{0.1} & 10 & $0 \pm 0 \mathrm{~d}$ & $5.3 \pm 3.5 f$ & $10.7 \pm 5.8 \mathrm{e}$ & $14.7 \pm 6.7 \mathrm{e}$ \\
\hline & 20 & $1.3 \pm 1.3 \mathrm{~cd}$ & $5.3 \pm 1.3 f$ & $10.7 \pm 3.5 \mathrm{e}$ & $18.7 \pm 1.3 \mathrm{de}$ \\
\hline & 30 & $1.3 \pm 1.3 \mathrm{~cd}$ & $12.0 \pm 4.0 \mathrm{ef}$ & $26.7 \pm 7.1 \mathrm{de}$ & $56.0 \pm 6.9 \mathrm{~cd}$ \\
\hline & 40 & $2.7 \pm 1.3 \mathrm{bcd}$ & $32.0 \pm 2.3 \mathrm{de}$ & $53.3 \pm 13.5 \mathrm{~cd}$ & $70.7 \pm 11.4 \mathrm{bc}$ \\
\hline & 50 & $2.7 \pm 1.3 \mathrm{bcd}$ & $46.7 \pm 2.7 \mathrm{~cd}$ & $69.3 \pm 7.1 \mathrm{bc}$ & $89.3 \pm 3.5 \mathrm{abc}$ \\
\hline & 60 & $4.0 \pm 0.0 \mathrm{abcd}$ & $65.3 \pm 2.7 \mathrm{bc}$ & $88.0 \pm 4.0 \mathrm{abc}$ & $94.7 \pm 3.5 \mathrm{ab}$ \\
\hline & 70 & $6.7 \pm 1.3 \mathrm{abc}$ & $57.3 \pm 7.1 \mathrm{~cd}$ & $84.0 \pm 4.6 a b c$ & $97.3 \pm 2.7 a$ \\
\hline & 80 & $9.3 \pm 1.3 \mathrm{ab}$ & $88.0 \pm 4.0 \mathrm{ab}$ & $94.7 \pm 1.3 \mathrm{ab}$ & $98.7 \pm 1.3 \mathrm{a}$ \\
\hline & 90 & $10.7 \pm 1.3 \mathrm{ab}$ & $90.7 \pm 2.7 \mathrm{ab}$ & $100 \pm 0 \mathrm{a}$ & $100 \pm 0 a$ \\
\hline & 100 & $14.7 \pm 1.3 \mathrm{a}$ & $93.3 \pm 3.5 a$ & $100 \pm 0 \mathrm{a}$ & $100 \pm 0 a$ \\
\hline \multirow[t]{7}{*}{1} & 10 & $10.7 \pm 1.3 \mathrm{e}$ & $72.0 \pm 2.3 d$ & $97.3 \pm 1.3 b$ & $100 \pm 0$ \\
\hline & 20 & $14.7 \pm 2.7 \mathrm{de}$ & $77.3 \pm 1.3 \mathrm{~cd}$ & $100 \pm 0 \mathrm{a}$ & $100 \pm 0$ \\
\hline & 30 & $20.0 \pm 2.3 \mathrm{de}$ & $86.7 \pm 1.3 \mathrm{bcd}$ & $100 \pm 0 \mathrm{a}$ & $100 \pm 0$ \\
\hline & 40 & $25.3 \pm 3.5 \mathrm{de}$ & $89.3 \pm 4.8 \mathrm{bcd}$ & $100 \pm 0 \mathrm{a}$ & $100 \pm 0$ \\
\hline & 50 & $29.3 \pm 2.7 \mathrm{de}$ & $93.3 \pm 3.5 \mathrm{abc}$ & $100 \pm 0 a$ & $100 \pm 0$ \\
\hline & 60 & $36.0 \pm 2.3 \mathrm{~cd}$ & $94.7 \pm 2.7 \mathrm{ab}$ & $100 \pm 0 a$ & $100 \pm 0$ \\
\hline & 70 & $57.3 \pm 9.3 b c$ & $100 \pm 0 \mathrm{a}$ & $100 \pm 0 \mathrm{a}$ & $100 \pm 0$ \\
\hline
\end{tabular}




$\begin{array}{lllll}80 & 66.7 \pm 9.3 \mathrm{ab} & 100 \pm 0 \mathrm{a} & 100 \pm 0 \mathrm{a} & 100 \pm 0 \\ 90 & 73.3 \pm 3.5 \mathrm{ab} & 100 \pm 0 \mathrm{a} & 100 \pm 0 \mathrm{a} & 100 \pm 0 \\ 100 & 84.0 \pm 2.3 \mathrm{a} & 100 \pm 0 \mathrm{a} & 100 \pm 0 \mathrm{a} & 100 \pm 0\end{array}$

$2{ }^{\mathrm{a}}$ For each spinosad rate and exposure time, means followed by different letters are significantly 3 different $(P<0.05$; by Bonferroni $t$-tests $)$.

4 


\section{Table 5}

2 Mortality of $R$. dominica adults on wheat with varying percentage of kernels treated with two

3 rates of spinosad dry formulation at different exposure times.

\begin{tabular}{|c|c|c|c|c|c|}
\hline \multirow{3}{*}{$\begin{array}{l}\text { Rate } \\
(\mathrm{mg} \text { a.i. } \\
\left.\mathrm{kg}^{-1}\right)\end{array}$} & \multirow{3}{*}{$\begin{array}{l}\text { Percentage of } \\
\text { kernels treated }\end{array}$} & \multicolumn{4}{|c|}{ Mean \pm SE mortality at exposure time in days ${ }^{\mathrm{a}}$} \\
\hline & & 1 & 3 & 5 & 7 \\
\hline & & & & & \\
\hline \multirow[t]{10}{*}{0.1} & 10 & $1.3 \pm 1.3 b$ & $2.7 \pm 1.3 \mathrm{e}$ & $6.7 \pm 1.3 \mathrm{e}$ & $13.3 \pm 3.5 \mathrm{e}$ \\
\hline & 20 & $5.3 \pm 1.3 \mathrm{ab}$ & $6.7 \pm 1.3 \mathrm{e}$ & $14.7 \pm 3.5 \mathrm{de}$ & $24.0 \pm 2.3 \mathrm{de}$ \\
\hline & 30 & $4.0 \pm 2.3 \mathrm{ab}$ & $9.3 \pm 2.7 \mathrm{e}$ & $20.0 \pm 4.6 \mathrm{de}$ & $46.7 \pm 7.4 \mathrm{~cd}$ \\
\hline & 40 & $8.0 \pm 2.3 \mathrm{ab}$ & $14.7 \pm 3.5 \mathrm{de}$ & $42.7 \pm 4.8 \mathrm{~cd}$ & $72.0 \pm 6.1 b c$ \\
\hline & 50 & $10.7 \pm 1.3 \mathrm{ab}$ & $34.7 \pm 4.8 \mathrm{~cd}$ & $62.7 \pm 7.1 c$ & $85.3 \pm 7.1 \mathrm{ab}$ \\
\hline & 60 & $5.3 \pm 1.3 \mathrm{ab}$ & $45.3 \pm 7.4 \mathrm{c}$ & $74.7 \pm 8.1 b c$ & $93.3 \pm 3.5 \mathrm{ab}$ \\
\hline & 70 & $14.7 \pm 3.5 \mathrm{a}$ & $57.3 \pm 4.8 b c$ & $93.3 \pm 4.8 \mathrm{ab}$ & $98.7 \pm 1.3 a$ \\
\hline & 80 & $12.0 \pm 2.3 \mathrm{ab}$ & $84.0 \pm 2.3 \mathrm{ab}$ & $94.7 \pm 3.5 \mathrm{ab}$ & $97.3 \pm 2.7 \mathrm{a}$ \\
\hline & 90 & $18.7 \pm 7.1 \mathrm{a}$ & $85.3 \pm 5.3 a$ & $96.0 \pm 0.0 \mathrm{ab}$ & $100 \pm 0 a$ \\
\hline & 100 & $13.3 \pm 1.3 \mathrm{a}$ & $85.3 \pm 4.8 \mathrm{a}$ & $100 \pm 0 \mathrm{a}$ & $100 \pm 0 \mathrm{a}$ \\
\hline \multirow[t]{7}{*}{1} & 10 & $2.7 \pm 2.7 \mathrm{e}$ & $62.7 \pm 8.1 c$ & $93.33 \pm 2.7 b$ & $100 \pm 0$ \\
\hline & 20 & $16.0 \pm 2.3 \mathrm{de}$ & $77.3 \pm 3.5 b c$ & $100 \pm 0 a$ & $100 \pm 0$ \\
\hline & 30 & $14.7 \pm 2.7 \mathrm{de}$ & $93.3 \pm 3.5 \mathrm{ab}$ & $100 \pm 0 \mathrm{a}$ & $100 \pm 0$ \\
\hline & 40 & $22.7 \pm 3.5 \mathrm{cde}$ & $90.7 \pm 3.5 \mathrm{abc}$ & $100 \pm 0 a$ & $100 \pm 0$ \\
\hline & 50 & $24.0 \pm 2.3 \mathrm{~cd}$ & $89.3 \pm 1.3 \mathrm{abc}$ & $100 \pm 0 a$ & $100 \pm 0$ \\
\hline & 60 & $37.3 \pm 1.3 \mathrm{bcd}$ & $92.0 \pm 4.6 a b$ & $100 \pm 0 \mathrm{a}$ & $100 \pm 0$ \\
\hline & 70 & $58.7 \pm 13.9 \mathrm{abc}$ & $94.7 \pm 1.3 \mathrm{ab}$ & $100 \pm 0 \mathrm{a}$ & $100 \pm 0$ \\
\hline
\end{tabular}




\begin{tabular}{|c|c|c|c|c|}
\hline 80 & $64.0 \pm 10.6 a b$ & $96.0 \pm 2.3 \mathrm{ab}$ & $100 \pm 0 a$ & $100 \pm 0$ \\
\hline 90 & $70.7 \pm 3.5 \mathrm{ab}$ & $98.7 \pm 1.3 \mathrm{a}$ & $100 \pm 0 \mathrm{a}$ & $100 \pm 0$ \\
\hline 100 & $81.3 \pm 6.7 a$ & $98.7 \pm 1.3 \mathrm{a}$ & $100 \pm 0 a$ & $100 \pm 0$ \\
\hline$d$ & exposure time, & as followed $b$ & ferent lette & ignificantly \\
\hline $05 ;$ by & ferroni $t$-tests). & & & \\
\hline
\end{tabular}


2 Fig. 1. Relationship between the percentage of kernels treated with spinosad by kernel dipping 3 method and the times for 50\% ( $\left.\mathrm{LT}_{50}\right)$ and $95 \%\left(\mathrm{LT}_{95}\right)$ mortality of $R$. dominica adults.

4

5 Fig. 2. Relationship between the percentage of kernels treated with two spinosad formulations by

6 admixture method and time for $>50 \%$ and $<100 \%$ mortality or $100 \%$ mortality of $R$. dominica

7 adults.

8 
2 Fig. 1. Relationship between the percentage of kernels treated with spinosad by kernel dipping

3 method and the times for 50\% ( $\left.\mathrm{LT}_{50}\right)$ and $95 \%\left(\mathrm{LT}_{95}\right)$ mortality of $R$. dominica adults. The $y$-axis

4 scale is different among the four graphs.

7 Fig. 2. Relationship between the percentage of kernels treated with two spinosad formulations by

8 admixture method and time for $>50 \%$ and $<100 \%$ mortality or $100 \%$ mortality of $R$. dominica

9 adults.

10 
Fig. 1
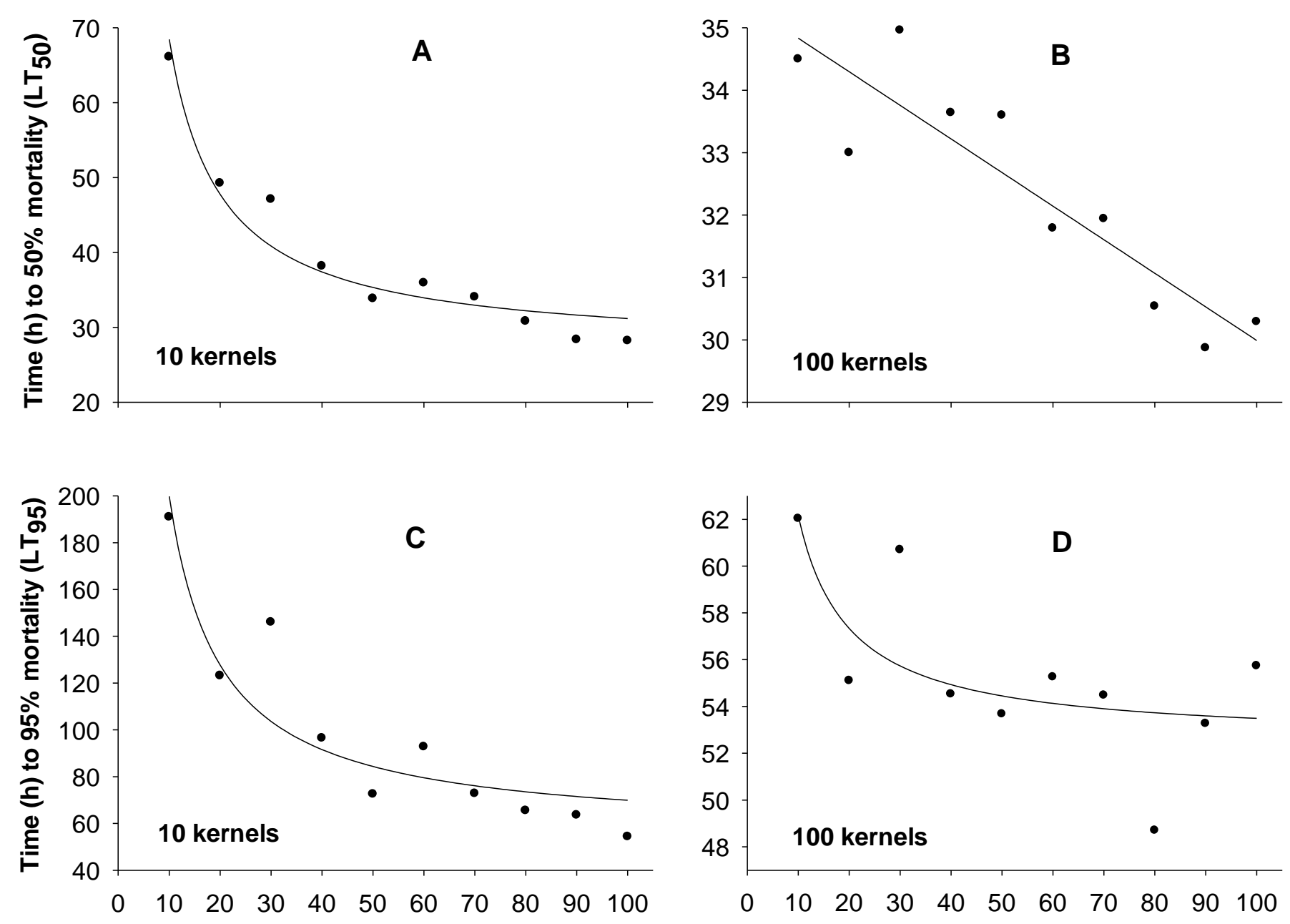

2
3

Percentage of kernels treated 
Fig. 2

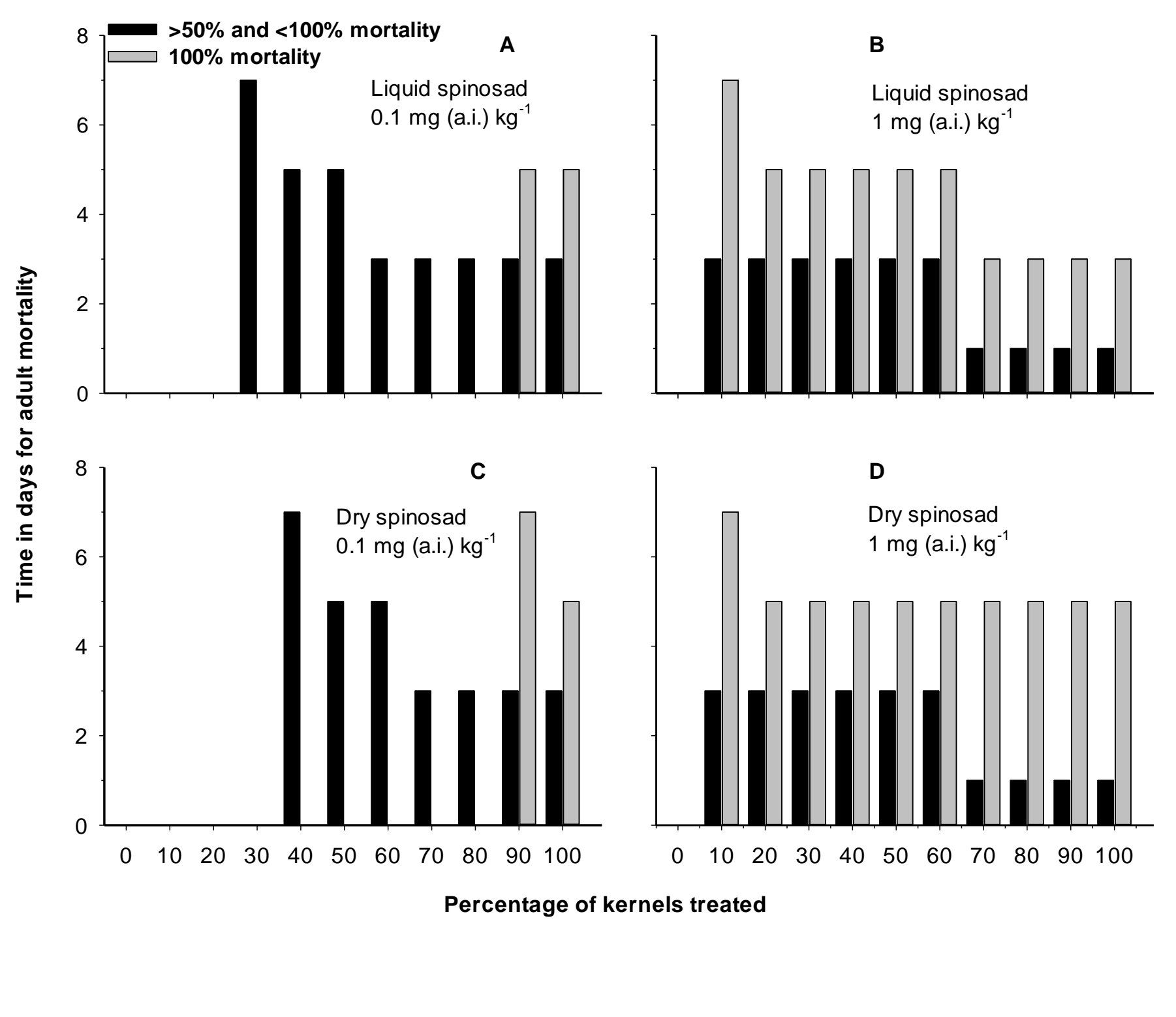

